\title{
The history of hydrocarbon filling of Danish chalk fields
}

\author{
Peter Frykman, Ole V. Vejbæk, Niels Bech and Carsten M. Nielsen
}

In an oil reservoir, the geometry of the interface between water and oil is critical in determining the volume of oil trapped below the top seal. If the interface is planar and horizontal, the volume calculation is fairly simple, but if the interface is tilted or undulating, estimation of the volume of the trapped oil is complex as it depends on the combined structural and fluid contact geometry. Since accumulation of the oil may take place over a time span of several million years, while the reservoir is experiencing burial and compaction, the charge history must be studied using dynamic methods that account for these changes and for flow in both the oil and water phases. These processes have been studied quantitatively at the Geological Survey of Denmark and Greenland (GEUS) in a project that has combined the burial model with a fluid flow simulator. The modelling study shows that filling of a chalk reservoir can have a very long and complex history dominated by very low fluid flow rates ( $\mathrm{cm} /$ year).
The resulting modelled present-day situation exhibits a very irregular oil distribution and a non-planar geometry of the fluid contacts, and shows marked similarities to that shown by the field data.

\section{Oil-water contact and free water level}

The positions of the oil-water contact (OWC), the gas-oil contact (GOC) and the associated free water level (FWL) in an oil- and gas-field are some of the most important factors in estimating the in-place hydrocarbon volumes of a given field. Thus it is important to be able to analyse and predict tilted or irregular fluid contacts (Dennis et al. 2000; Moss et al. 2003; Dennis et al. in press; Vejbæk et al. in press).

The fluid contact can be defined in two radically different ways: The OWC is defined by setting a threshold for the oil saturation, whereas the FWL is defined where the pressures

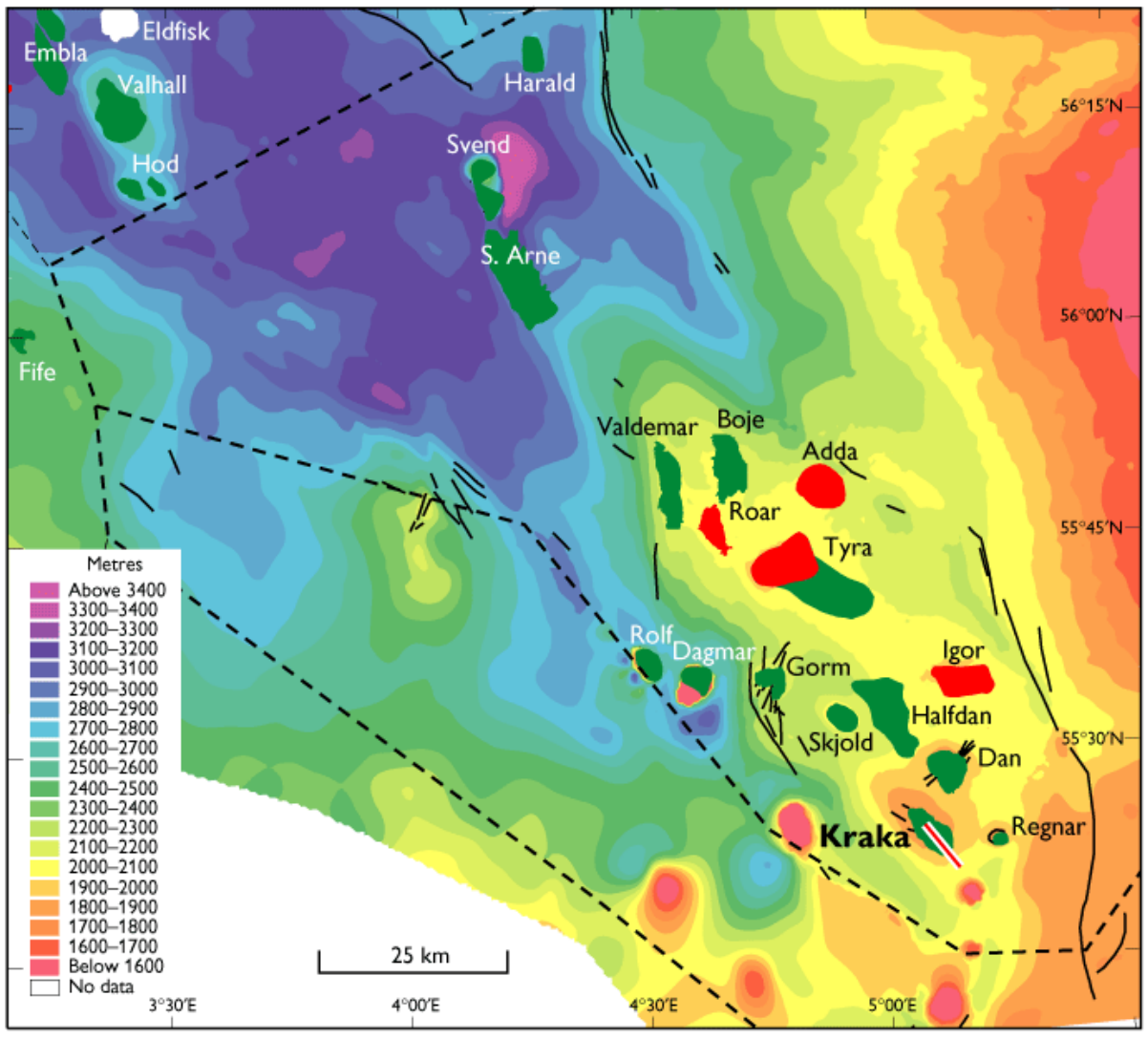

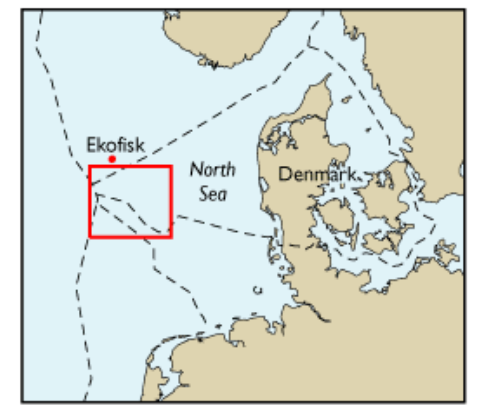

Fig. 1. Map showing top chalk depth structure for the Danish North Sea area. Producing chalk fields are shown, with oil fields green, and gas fields red. Colour interval is $100 \mathrm{~m}$ and contour interval $50 \mathrm{~m}$. The red line on the Kraka field shows location of the profile studied (see Fig. 3). Full black lines are major faults. Dashed black lines are offshore sector boundaries. Modified from Vejbæk et al. (in press). 
A

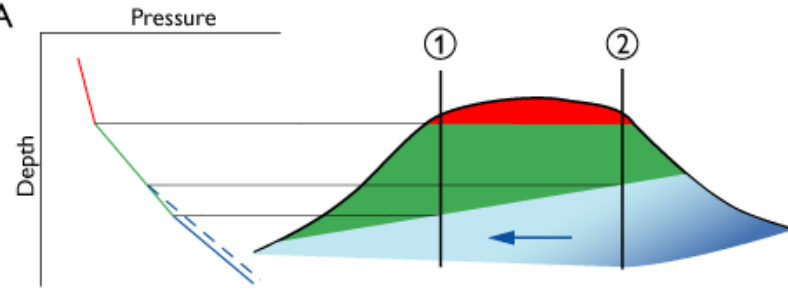

B

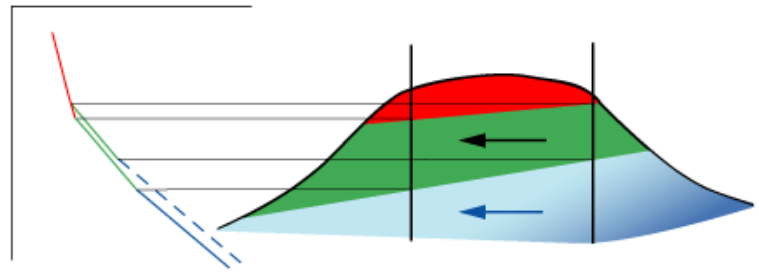

C

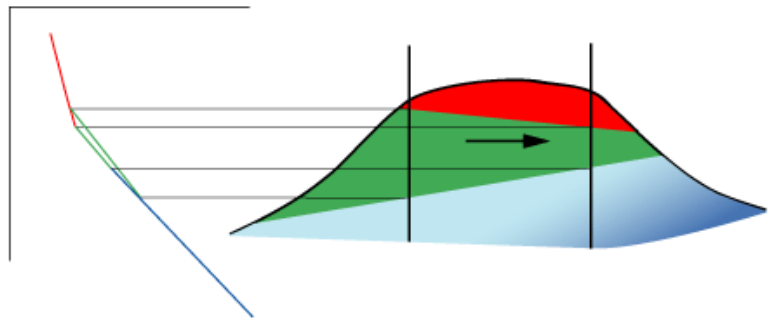

$\square$ Gas

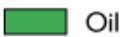

Oil

- - -Water pressure at 2

Fig. 2. Possible dynamic equilibrium situations that may fit a tilted oil-water contact. Arrows show direction of pressure drop corresponding to flow direction. $\mathbf{1}$ and $\mathbf{2}$ represent wells where the pressure depth plots shown to the left are generated: (A) only the water phase is dynamic; (B) both oil and water are flowing, but the tilt is maintained due to a higher lateral pressure gradient in the water phase; (C) the tilt is maintained only by an oil phase gradient. The situations are physically distinguishable by the dip of the gas-oil contact. Modified from Vejbæk et al. (in press).

in the water and the oil phases are equal. In the chalk reservoirs in the North Sea, the relationship between the OWC and the FWL can be described in simple cases by the capillary characteristics of the reservoir rock.

In the central North Sea (Fig. 1), the fluid contacts in the Chalk can be naturally tilted by hydrodynamic activity due to a regional flow of water in the chalk. A regional pressure gradient in the chalk aquifer has been described from available pressure measurements (Megson 1992), and later refined using more data (Dennis et al. in press).

The regional lateral pressure gradient reflects differential compaction caused by rapid Neogene deposition with the highest burial rates in the central Ekofisk area (Japsen 1998). The water therefore migrates laterally away from this area and towards the periphery of the North Sea.
Analysis of burial history by backstripping and decompaction shows that this pressure was probably caused mainly by rapid deposition in the time interval from latest Miocene to Recent times, as the magnitude of the pressure corresponds to the thickness of these deposits (Japsen 1998). This is consistent with a very low regional permeability of the chalk (and adjacent sedimentary packages) probably not exceeding $1 \mathrm{mD}$.

The flow of water and the accompanying pressure differences will influence the position of the FWL (Fig. 2A). If the oil is also flowing due to either buoyancy equilibration or active migration, it will affect both the FWL and the GOC (Fig. 2B, C).

Factors that modify the position of the FWL include tilting due to structural movements, and the presence of oil migrating from the underlying source rocks into the reservoir. The reason that these processes influence the present geometry of the FWL is that both oil and water flow take place at very low velocities ( $\mathrm{cm} /$ year), due to the low permeability of the chalk. Even though structural movements are very slow, the flow is not able to respond quickly enough to equilibrate the system, even on a scale of millions of years.

The petrophysical properties of the North Sea chalk reservoirs are mainly governed by their high-porosity/low-permeability aspect with porosities usually around $20-40 \%$ and average permeability of $1 \mathrm{mD}$.

\section{Case study}

The Kraka field in the southern Danish North Sea (Fig. 1) has been chosen as the subject of a case study of primary oil charging and remigration. To study the interaction of the different processes, reservoir fluid flow simulation techniques have been applied in combination with burial modelling, including compaction (Vejbæk 2002). The results show that a time span in the order of $2 \mathrm{Ma}$ is required for the hydrocarbons to reach the top of the reservoir in an approximately equilibrium state, if they enter the reservoir section from a flank position. However, not even dynamic equilibrium can be fully obtained in this time span if re-perturbation by structural movements leads to changing water-zone pressure gradients.

The study is focused on a $2 \mathrm{D}$ section from the crestal part through the south-eastern flank of the Kraka field (Figs 1, 3). Since porosity is the main cause for changes in seismic impedance (Japsen et al. in press), detailed porosity profiles can be achieved by converting acoustic impedance derived by seismic inversion. These porosity profiles have been modified by backstripping to reconstruct geometry and porosity. As flow simulation has only been applied to the Chalk Group layers, 
Fig. 3. Modelled oil saturation in the Kraka field profile at different times during the simulated filling history. Top structures of the Ekofisk (Maastrichtian) and Tor (Danian) Formations are shown as thin green and red lines, respectively. Calculated free water levels (FWLs) for these two reservoir units are shown in thicker green and red lines, respectively. Charging of the reservoir starts at 8 Ma B.P. by injecting oil at a very low rate at the flank position shown with an arrow. A: The situation after 250000 years, where the injected oil is preferentially moving in the Maastrichtian reservoir unit. B: Oil distribution after $2 \mathrm{Ma}$, where the charging has been sustained over the first $1 \mathrm{Ma}$, accompanied by equilibration during continued burial. C: Oil is near-equilibrium at 4 Ma B.P. D: Tilted FWLs resulting from a lateral pressure gradient of $3.5 \mathrm{psi} / \mathrm{km}(24.1 \mathrm{kPa} / \mathrm{km})$ applied for $1 \mathrm{Ma}$ (from 2 to $1 \mathrm{Ma}$ B.P.) within the water phase. This causes a water-flow south-eastwards in the aquifer, and accordingly a tilting of the FWL in that direction, which is further accentuated until the modelled present-day situation shown in E. Modified from Vejbæk et al. (in press).

detailed porosity profiles have only been constructed for these layers.

The simulation of flow processes in chalk reservoirs is characterised by the need for end-point scaling and hysteresis, in order to account for the marked influence from the high capillary forces in this low-permeability medium. Since the dominant process during the filling history is a drainage process (i.e. oil replacing water), the saturation functions must also be derived for this type of process. There is a general lack of relative permeability analyses for drainage, and therefore imbibition curves have been the guide for establishing the drainage saturation functions for relative permeability.

For each rock type (Danian and Maastrichtian), the irreducible water saturation $\left(S_{w i}\right)$ and capillary entry pressure $\left(P_{c e}\right)$ are assumed to depend upon the porosity $(\phi)$ through relatively simple relationships. Using these relationships, the primary drainage capillary pressure is described by means of the EQR model (Engstrøm 1995).

The simulation of the filling history uses 8 million years before present as the starting point, and the entry of hydrocarbons from an underlying source rock is assumed to occur on the south-eastern flank (Fig. 3).

The flow simulation of the filling dynamics of the Kraka chalk reservoir has a complex geometry due to the high capillary entry pressures in the low-permeability chalks. These internal barriers re-direct hydrocarbons, such that oil flows in the Maastrichtian layers for some time before it is able to penetrate upwards into the overlying Danian chalk (Fig. 3A).

If oil supply is stopped after 1 million years, the oil continues to move towards the crest, but leaves immobile residual oil on the migration route. Hydrocarbon charging is slow and equilibration of hydrocarbons with respect to pressure gradients therefore occurs very slowly.
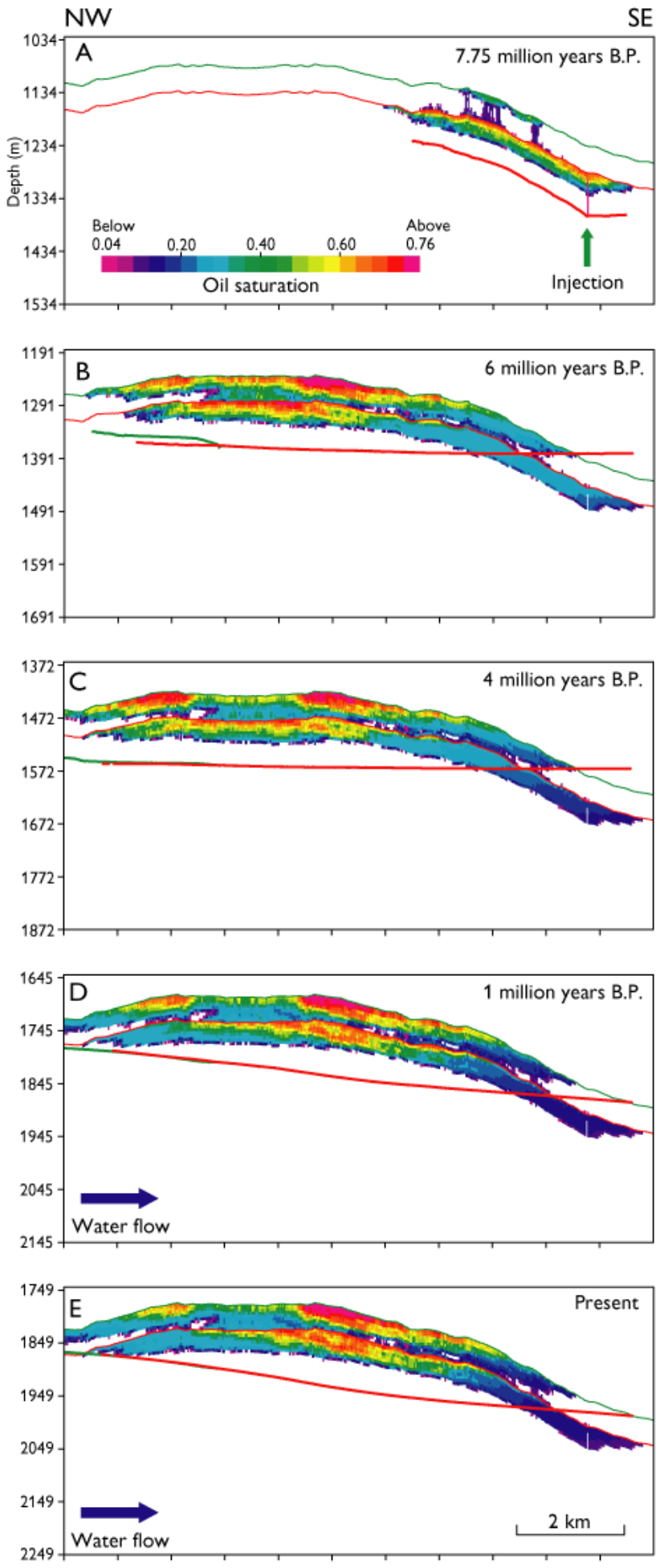

After two million years, the oil is seen to be nearly in equilibrium even though the FWLs are still slightly inclined and do not coincide for the two reservoir units (Fig. 3B). After 4 million years, equilibrium is more obvious (Fig. 3C). Between 2 million years before present and the present, a 
pressure gradient is imposed in the water zone in order to allow for the regional pressure distribution during that period. As a result, the oil is forced south-eastwards towards the flank (Fig. 3D), which is further accentuated through time as the water gradient is sustained (Fig. 3E). Again a zone with residual oil is left behind.

\section{Conclusions}

The modelling reported here demonstrates that oil accumulations in chalk may require several million years to equilibrate following perturbations resulting from primary migration or reservoir tilting, if matrix permeability governs fluid flow. Since naturally occurring disequilibrium oil accumulations dominate the Danish chalk fields, it must be concluded that matrix flow dominates fluid dynamics. The modelled filling scenarios are intended to illustrate the general aspects of geological timescale oil-water dynamics in chalk reservoirs. The scenarios are not considered to represent actual filling histories, as they are constrained by relatively simple model assumptions, but they are geologically plausible. Due to the long equilibration times, it can be dangerous to interpret tilted contacts as reflecting only dynamic equilibrium, as they may be fully dynamic and still actively flowing. This is revealed locally by non-equilibrium between Danian and Maastrichtian oil where they are seen to have different FWLs. It is important to try to understand fluid dynamics during exploration work, since this strongly affects trap definition and volumes. The project shows that with simple and geologically based assumptions, a reasonable filling history can be modelled quantitatively. A reasonable end-result can be produced that has many similarities with present-day hydrocarbon configurations. With the methods developed in the project, even a fully dynamic system (with both oil and water moving), as for example in the Dan-Halfdan field system, may be explained.

\section{Acknowledgement}

The work presented in this paper was partly funded by the Danish Energy Authority (Grant no. 1313/01-0004).

\section{References}

Dennis, H., Baillie, J., Holt, T. \& Wessel-Berg, D. 2000: Hydrodynamic activity and tilted oil-water contacts in the North Sea. In: Ofstad, K., Kittilsen, E.-J. \& Alexander-Marrack, P. (eds): Improving the exploration process by learning from the past. Norwegian Petroleum Society (NPF), Special Publications 9, 171-185.

Dennis, H., Bergmo, P. \& Holt, T. in press: Tilted oil-water contacts modelling the effects of aquifer heterogeneity. In: Doré A.G. \& Vining, B. (eds): Petroleum geology: North-West Europe and global perspectives. Proceedings of the 6th Petroleum Geology Conference. London: Geological Society.

Engstrøm, F. 1995: A new method to normalize capillary pressure curves. 1995 International Symposium of the Society of Core Analysts, San Francisco, CA, USA, September 12-14, 1995, SCA-9535, 12 pp.

Japsen, P. 1998: Regional velocity-depth anomalies, North Sea Chalk; a record of overpressure and Neogene uplift and erosion. American Association of Petroleum Geologists Bulletin 82(11), 2031-2074.

Japsen, P., Bruun, A., Fabricius, I.L., Rasmussen, R., Vejbæk, O.V., Pedersen, J.M., Mavko, G. \& Mogensen, C. in press: Influence of porosity and pore fluid on acoustic properties of chalk: AVO-response from oil, South-Arne Field, North Sea. Petroleum Geoscience.

Megson, J.B. 1992: The North Sea chalk play: examples from the Danish Central Graben. In: Hardman, R.F.P. (ed.): Exploration Britain: geological insights for the next decade. Geological Society (London) Special Publication 67, 247-282.

Moss, B., Barson, D., Rakhit, K., Dennis, H. \& Swarbrick, R. 2003: Formation pore pressures and formation waters. In: Evans, D. et al. (eds): The Millenium Atlas: petroleum geology of the central and northern North Sea, 317-329. London: Geological Society.

Vejbæk, O.V. 2002: A 1, 2 and 3D backstripping procedure with application to the Kraka field. Danmarks og Grønlands Geologiske Undersøgelse Rapport 2002/44, 35 pp.

Vejbæk, O.V., Frykman, P., Bech, N. \& Nielsen, C.M. in press: The history of hydrocarbon filling of chalk fields. In: Doré, A.G. \& Vining, B. (eds): Petroleum geology: North-West Europe and global perspectives. Proceedings of the 6th Petroleum Geology Conference. London: Geological Society.

\footnotetext{
Authors' addresses

P.F., O.V.V. \& N.B., Geological Survey of Denmark and Greenland, Øster Voldgade 10, DK-1350 Copenhagen K, Denmark. E-mail: pfr@geus.dk

C.M.N., Danish Energy Authority, Amaliegade 44, DK-1256 Copenhagen K, Denmark.
} 